\title{
POLLUTION ABATEMENT \\ COSTS, REGULATION, AND \\ PLANT-LEVEL PRODUCTIVITY
}

\begin{abstract}
We analyze the connection between productivity, pollution abatement expenditures, and other measures of environmental regulation for plants in three industries (paper, oil, and steel). We examine data from 1979 to 1990 , considering both total factor productivity levels and growth rates. Plants with higher abatement cost levels have significantly lower productivity levels. The magnitude of the impact is somewhat larger than expected: $\$ 1$ greater abatement costs appears to be associated with the equivalent of $\$ 1.74$ in lower productivity for paper mills, $\$ 1.35$ for oil refineries, and $\$ 3.28$ for steel mills. However, these results apply only to variation across plants in productivity levels. Estimates looking at productivity variation within plants over time, or estimates using productivity growth rates show a smaller (and insignificant) relationship between abatement costs and productivity. Other measures of environmental regulation faced by the plants (compliance status, enforcement activity, and emissions) are not significantly related to productivity.
\end{abstract}

Wayne B. Gray Department of Economics

Clark University Worcester, MA 01610 and NBER
Ronald J. Shadbegian

Department of Economics

University of Massachusetts, Dartmouth North Dartmouth, MA 02747 


\author{
POLLUTION ABATEMENT \\ COSTS, REGULATION, AND \\ PLANT-LEVEL PRODUCTIVITY
}

Wayne B. Gray

Ronald J. Shadbegian

Working Paper No. 4994

\author{
NATIONAL BUREAU OF ECONOMIC RESEARCH \\ 1050 Massachusetts Avenue \\ Cambridge, MA 02138 \\ January 1995
}

We gratefully acknowledge support from the Census Bureau Research Fellow Program and the Environmental Protection Agency (Grant R81-9843-010). Partial support for data creation came from NSF Grant SES-8921277. The research was carried out at the Census Bureau's Boston Research Data Center. We have benefitted from comments and assistance from Ernst Berndt, Mark Doms, Mary Streitwieser, Arnold Reznek, and Robert McGuckin, as well as seminar participants from many groups including the Census Bureau and NBER. This paper is part of NBER's research program in Productivity. Any opinions expressed are those of the authors and not those of the National Bureau of Economic Research, or any of the supporting agencies. Any remaining errors or omissions are, of course, ours.

(C) 1994 by Wayne B. Gray and Ronald J. Shadbegian. All rights reserved. Short sections of text, not to exceed two paragraphs, may be quoted without explicit permission provided that full credit, including $\odot$ notice, is given to the source. 


\section{Introduction}

Environmental regulations have often been criticized for imposing excessive costs and reducing the competitiveness of U.S. firms. In 1990 the U.S. manufacturing sector reported over $\$ 17$ billion in operating costs and $\$ 6$ billion in capital expenditures for pollution abatement, based on a Census Bureau survey. However, abatement costs may be difficult to measure (design costs for a new production process) or not covered by the survey (managerial attention absorbed by required paperwork), leading to an understatement of true abatement costs. Alternatively, forcing firms to pursue cleaner technologies could encourage innovation and lead to gains in competitiveness, so regulation might raise productivity (associated with the 'Porter hypothesis' - Porter $(1990 ; 1991))$.

Instead of relying exclusively on survey evidence, it may be possible to measure abatement costs indirectly, through their impact on productivity. Productivity is defined as output per unit of inputs, so pollution abatement spending should reduce productivity: increasing inputs without creating more output. In fact, the quantitative impact of abatement costs on productivity should be equal to their share in the firm's total cost (Gray (1987)). A greater than expected effect of abatement costs on productivity indicates that abatement costs are understated; a smaller than expected effect on productivity indicates an overstatement of abatement costs (or some offsetting benefits from regulation).

Several studies have examined the impact of environmental regulation on productivity. Some use estimates of compliance costs to calculate productivity effects (e.g. the 'growth accounting' work of Denison (1979)). Others use econometric analysis with plant-level (Gollop and Roberts (1983)) or industry-level (Gray (1986; 1987), Barbera and McConnell 
(1986)) data to test for regulation's impact on productivity. The latter studies tend to find that regulation significantly affects productivity, with more regulated plants or industries having lower productivity levels and slower productivity growth. The former tend to stress that compliance costs are a small part of total cost, so that the impact on productivity is likely to be small. Of course, both views could be correct: the impact could be small, but statistically significant. Little is known about the magnitude of regulation's impact during the 1980s, and prior studies have not combined productivity and compliance cost data at the plant-level.

In this paper, we analyze plant-level productivity data for three industries, taken from the Longitudinal Research Database (LRD). This data was developed by the Center for Economic Studies in the Census Bureau, and we are using the data at the Census's Boston Research Data Center. Our data includes 117 pulp and paper mills (SIC 2611 and 2621), 101 oil refineries (SIC 2911), and 51 steel mills (SIC 3312). We have information on pollution abatement expenditures, along with enforcement, compliance, and emissions data for the 1979-1990 period. We focus on total factor productivity (TFP), examining both productivity levels and growth rates for each plant, and their relationship to the regulatory measures.

We find that plants which spend more on pollution abatement, one measure of regulatory impact, are significantly less productive. A plant with $\$ 1$ higher abatement costs tends to have the equivalent of $\$ 1.74$ lower productivity in paper, $\$ 1.35$ lower in oil, and $\$ 3.28$ lower in steel. These coefficients suggest that the survey estimates of abatement costs are understated. However, we find smaller and less significant results when we look at 
changes in abatement costs over time. Other regulatory measures (enforcement, compliance, and emissions) are not significantly related to productivity, and their impacts vary across industries, though their signs tend to point in the same direction (more regulation is associated with lower productivity).

In earlier work (Gray and Shadbegian, 1993) we found larger productivity impacts of differences in abatement costs across plants, with $\$ 1$ of abatement costs reducing productivity by $\$ 2.26$ for paper, $\$ 2.38$ for oil, and $\$ 4.19$ for steel. Perhaps more importantly, the earlier paper found that plants with growing abatement costs had significantly lower productivity growth, so those results were consistent, whether for levels or for changes. Our earlier work used fewer years of data (1979-1985), and a different measurement procedure which may have biased the coefficient estimates (see Section 3 below).

Properly interpreting our current results is tricky, since the results for productivity levels and productivity changes are different. One possibility is that abatement costs affect productivity, but that measurement error on abatement costs affects the productivity change estimation, biassing down those coefficients. Another interpretation is that there are 'good' and 'bad' plants: good plants are more productive, more likely to comply with regulations, and more clever about discovering low-cost means of compliance. Since most of the variation in abatement costs comes across plants, it is difficult to separately identify the impact of unmeasured (and persistent) plant quality. Including lagged productivity levels in our regressions yields strong evidence for persistence in plant productivity, but reduces the estimated impact of abatement costs on productivity by only about one-quarter in each industry. 
In section Il we discuss various reasons why regulation might affect a plant's productivity. We address the data sources used and various econometric issues in section III. The results are presented in section IV, with conclusions in section V.

\section{Does Regulation Hurt (or Help) Productivity?}

According to standard economic analysis, government regulation ought to reduce productivity. With firms assumed to choose the best (profit-maximizing) combinations, regulations that constrain these choices will tend to force plants away from the optimum production decisions. Increases in regulation could also lead firms to become more uncertain about future regulatory demands. This may lead them to postpone investment (Viscusi 1983), the development of new products (Hoerger, Beamer, and Hanson 1983), or research on new production processes. Similar effects could result if firms had a limited budget for research and development, and regulation required them to investigate cleaner technologies rather than more productive ones. New plants generally face more stringent rules, and current regulations tend to be written for existing technologies, which further discourages the building of new plants or development of new technologies.

In addition to these constraints, most regulations force firms to use inputs directly for regulatory compliance: a scrubber on a smokestack, a water treatment plant, or clerks to fill out government forms. Existing measures of productivity do not distinguish between inputs used for production and inputs used for regulatory compliance, so inputs are overstated and productivity is understated. This 'mismeasurement' effect, added to the constraints described 
above, drive the prevailing view that plants facing more regulation should have lower productivity.

The opposing view, that regulation can increase productivity, is necessarily based on the notion that firms were not really behaving optimally (in productivity terms) before the regulation was imposed. One possibility is the presence of ' $\mathrm{X}$-inefficiency' (Leibenstein 1960), where workers and managers don't bother to work their hardest unless prodded by an outside stimulus such as regulation (see Clark (1980) for a similar effect following the unionization of cement plants). New, cleaner equipment may also be more productive than the old equipment it replaces, although for this to represent a productivity gain from regulation we have to assume that the plant would not have installed the new equipment without the regulatory pressures.

Recent suggestions that regulation could have a beneficial impact on the economy are based on anecdotal observations that some firms, forced to modify their production processes for environmental reasons, later found that the new process was also superior in strictly economic terms. ${ }^{1}$ The savings often come from redesigning processes to eliminate waste and recycle production by-products (so-called 'closed loop' production methods). Supporters of stricter regulation often point to such examples, but fail to consider the costs of making these innovations: if firms had been free to innovate in any direction they chose, they might have achieved even greater improvements in productivity. Regulation can only improve a firm's innovation if the firm is making some systematic errors. This could be due to X-

' Oates, Palmer, and Portney (1994) discuss several issues associated with the argument that stringent regulation can provide economic benefits. 
inefficiency in technology choice, if firms complacently accept current production methods rather than aggressively seeking new ones.

Some advantages attributed to regulation would not show up for many years, and are unlikely to be captured in our data. Porter $(1990 ; 1991)$ argues that the demand for 'clean' production technologies will greatly increase in the future, and that firms (or countries) which develop the technology first will have competitive advantages in later years. Again, this argument assumes that firms fail to recognize, or have difficulty appropriating, the gains from the technology, so that regulation is needed to induce the development. Some proponents of economic benefits arising from regulation also argue for more incentive-based regulation, encouraging innovation and developing new markets. Since our data is based on existing regulation, we may find higher costs (and less scope for productivity benefits) than would arise from some future, more efficiently designed regulatory system.

III. Data and Estimation Issues

Our major source of plant-level data is the Longitudinal Research Database (LRD) maintained by the Center for Economic Studies at the Census Bureau. ${ }^{2}$ The LRD contains annual data for U.S. manufacturing plants from the Annual Surveys and Censuses of

2 For a detailed description of the LRD data, see McGuckin and Pascoe (1988). Several published studies have examined productivity issues using the LRD, including Lichtenberg and Siegel (1990a and 1990b) and Nguyen and Kokkelenberg (1992). 
Manufactures from 1972 through 1990. Using these data, we calculate productivity levels and growth rates for the three industries in our sample (paper, oil, and steel). We selected plants with continuous LRD data through the period, and with adequate data to construct a capital stock measure, dropping a few plants with implausible values for key variables. Our plants tend to be very large, since these are more likely to have continuous LRD data, so our sample includes 60 percent of total industry shipments for paper, 70 percent for oil, and 65 percent for steel.

We also have plant-level data on compliance costs from the Census Bureau's Pollution Abatement Costs and Expenditures (PACE) survey, done annually since $1973 .{ }^{3}$ We work with the PACE surveys beginning from 1979 (the oldest available year of data) through 1990. The PACE survey samples about 20,000 plants each year, concentrating on large plants in heavily polluting manufacturing industries. The plants are asked about both new capital expenditures and total annual operating costs for pollution abatement. We measure compliance costs as the plant's annual operating cost for pollution abatement.

We concentrate on operating costs rather than new capital expenditures for both theoretical and practical reasons. First, we would expect current production to be affected by the entire stock of existing pollution abatement capital, not just this year's capital expenditures. Much of these industries' investment in pollution abatement capital occurred before 1979 (when our data begins), so we cannot calculate accurate pollution abatement capital stocks for our plants. In addition, the operating cost measure is already a 'total cost'

3 The survey was not done in 1987, due to budget difficulties. We interpolated the 1987 values, based on information from the 1986 and 1988 surveys. 
measure, because it includes depreciation and amortization of existing pollution abatement capital. Finally, we are able to impute pollution abatement operating costs for years in which the plant was missing from the PACE sample, based on the plant's data in other years. ${ }^{4}$ Since capital expenditures exhibit larger year-to-year fluctuations, a similar imputation procedure would be more problematic.

We also use information from EPA's own regulatory datasets. We collected plantlevel data from the Compliance Data System (CDS) on air pollution inspections (both federal and state), as well as total enforcement actions. This serves as a proxy for the intensity of regulatory enforcement faced by the plant, and is expected to be negatively related to productivity. ${ }^{5}$ If a plant did not appear in the CDS, we assume that it did not receive any enforcement (only a few plants were missing from the CDS data). The CDS data also provides annual information on the plant's compliance with air pollution regulations. Data from the National Emissions Data System (NEDS) gives the plant's emissions of common air pollutants, with periodic updates to reflect changes in the emissions over time. We concentrate on air pollution data because the EPA's water pollution data is not fully available until the late 1980s.

We use the value of shipments (adjusted for inventory changes and deflated by the industry price of shipments) to measure a plant's output. To calculate total factor

4 In each year some plants are missing from the sample, so requiring plants to be present every year from 1979 to 1990 would reduce our sample sizes by more than one-third.

${ }^{5}$ Deily and Gray (1991) find that steel mills facing more enforcement were more likely to be closed; Gray (1987) finds that industries facing more enforcement had a greater productivity slowdown. 
productivity (TFP), we calculate the difference between output $(\mathrm{Q})$ and the weighted average of three inputs: labor (L), materials and energy expenditures $(\mathrm{M})$ and capital stock $(\mathrm{K}):^{6}$

(1) $\quad$ TFP $=\log (\mathrm{Q})-\mathrm{a}_{\mathrm{L}} \log (\mathrm{L})-\mathrm{a}_{\mathrm{M}} \log (\mathrm{M})-\mathrm{a}_{\mathrm{K}} \log (\mathrm{K})$.

We obtain the factor weights $\left(a_{L}, a_{M}\right.$, and $\left.a_{K}\right)$ for the TFP calculation by regressing $\log (\mathrm{Q})$ on $\log (\mathrm{L}), \log (\mathrm{M}), \log (\mathrm{K})$ and year dummies for each of the three industries, using the 1979 to 1990 LRD data. The results of these regressions are as follows:?

(2)

$$
\begin{aligned}
& \text { paper: } \log (\mathrm{Q})=\begin{array}{c}
1.255 \\
(.089)
\end{array}+\underset{(.01)}{0.20 * \log (\mathrm{L})}+\begin{array}{l}
0.65 * \log (\mathrm{M}) \\
(.02)
\end{array}+\begin{array}{ll}
0.14 * \log (\mathrm{K}) & \mathrm{R}^{2}=.94 \\
\mathrm{~N}=1414
\end{array} \\
& \text { oil: } \log (\mathrm{Q})=\begin{array}{l}
0.886 \\
(.078)
\end{array}+\begin{array}{l}
0.036 * \log (\mathrm{L}) \\
(.011)
\end{array}+\begin{array}{l}
0.90 * \log (\mathrm{M}) \\
(.01)
\end{array}+\begin{array}{l}
0.04 * \log (\mathrm{K}) \\
(.01)
\end{array} \quad \begin{array}{l}
\mathrm{R}^{2}=.98 \\
\mathrm{~N}=1212,
\end{array}
\end{aligned}
$$

steel: $\log (\mathrm{Q})=\begin{aligned} & 1.650 \\ & (.108)\end{aligned}+\underset{(.01)}{0.31 * \log (\mathrm{L})}+\underset{(.02)}{0.64 * \log (\mathrm{M})}+\underset{(.02)}{0.04 * \log (\mathrm{K})} \quad \begin{aligned} & \mathrm{R}^{2}=.96 \\ & \mathrm{~N}=612\end{aligned}$

Note that these production functions do quite well in explaining the variation of output across plants and over time, leaving only $2-6 \%$ of output variation to be explaining by other factors (such as regulation).

These productivity calculations assume that all of the measured inputs are used to produce output. When some inputs are used for compliance with regulation (such as

${ }^{6}$ This is equivalent to assuming a three-input Cobb-Douglas production function: $\mathrm{Q}=\mathrm{A}^{*} \mathrm{~L}^{\mathrm{aL}} * \mathrm{M}^{\mathrm{aM}} * \mathrm{~K}^{\mathrm{aK}}$, where $\mathrm{A}$ is a 'productivity index' (and TFP $=\log (\mathrm{A})$ in equation (1)).

7 The factor weights derived from these regressions are similar to those that would be obtained if we used ex-post cost shares to calculate weights. 
pollution abatement expenditures), the measured inputs will overstate the amounts of inputs actually used in production, understating 'true' productivity. This 'mismeasurement' effect of regulation on measured TFP can be approximated by the share of compliance costs in total costs, as shown in Gray (1987). Using '*' to represent 'true' TFP and 'true' inputs (excluding compliance costs), we have:

$$
\begin{aligned}
\text { TFP* } & =\log (Q)-a_{L} \log \left(L^{*}\right)-a_{M} \log \left(M^{*}\right)-a_{K} \log \left(K^{*}\right) \\
& =\log (Q)-a_{L} \log \left(L-L_{R}\right)-a_{M} \log \left(M-M_{R}\right)-a_{K} \log \left(K-K_{R}\right) \\
& =T F P+a_{R},
\end{aligned}
$$

where the $R$ subscript refers to inputs used for regulatory compliance, and $a_{R}$ indicates the share of compliance costs in total costs.

Since our TFP measure is already in logarithmic form, differences across plants in compliance cost shares translate into percentage differences across plants in measured TFP. If plant A spends one percent of its total cost on compliance and plant B spends three percent, the level of measured TFP at plant A should be two percentage points higher than at plant B. Regressing TFP levels on compliance cost shares would lead to a coefficient of minus one. A similar relationship, with expected coefficients of minus one, holds between productivity growth rates and changes in compliance costs.

Several problems arise which may bias the regression coefficient away from minus one. The first is the issue of properly 'scaling' the compliance costs to allow for differences in plant size. The same dollar amount of pollution abatement expenditures could be huge for one plant and tiny for another plant, relative to their production. If one paper mill produces $\$ 200$ million of paper each year and another produces only $\$ 20$ million, $\$ 1$ million of 
pollution abatement spending would be 5 percent of output for the smaller plant, but only 0.5 percent for the larger - the difference between a very heavily regulated plant and a lightly regulated one. Thus we need to divide pollution abatement costs by a measure of the plant's size.

In our earlier paper, we divided each year's pollution abatement spending by the value of the plant's output in that year. This seems a natural way to account for plant size, but it can cause problems, especially for analyses looking at productivity changes over time. When a plant's output increases substantially (moving from a recession to a boom, for example), its productivity also tends to increase substantially. Pollution abatement expenditures tend not to change as quickly, so abatement costs divided by output tends to fall in these years. This seems to have influenced our earlier results, leading to a negative connection between changes in productivity and changes in the 'scaled' abatement cost measure.

In our current paper, we divide pollution abatement costs by a fixed measure of the plant's capacity (based on the plant's top two years of output). Because this capacity measure does not change from year to year, no negative connection with productivity changes is generated by the scaling factor. This helps explain why our current results do not find a significant effect of abatement costs on productivity changes.

A second issue is the exogeneity of our regulatory measures: does high abatement spending 'cause' low productivity, or does low productivity 'cause' high abatement spending? To test this, we can model the determinants of abatement costs, using variables which are clearly exogenous (not determined by either current productivity or current regulation). We 
then calculate unexplained (actual-predicted) abatement costs and enter this along with actual abatement costs in a second-stage regression of productivity on abatement costs. A significant coefficient on the unexplained abatement costs raises the possibility that productivity is directly affecting regulation (through the part of regulation not captured by the predicted value).

A third possible complication is that both regulation and productivity may be affected by other unmeasured factors. One likely candidate is the quality of the plant's management: good managers might run things more efficiently for both production and compliance, raising productivity and lowering pollution abatement costs. This would tend to create a negative correlation between abatement costs and productivity. We test for this bias by including the plant's past productivity in a regression of productivity on abatement costs, to see whether the coefficient on abatement costs is greatly reduced (a sign of omitted variable bias).

A fourth and final factor that might influence the estimated coefficient is the presence of measurement error, especially in the abatement cost variable. Because it is difficult to measure abatement costs, and because the survey considers primarily the capital side of abatement costs (the maintenance and operation of pollution control equipment), the survey results may give only an approximate picture of true abatement costs. If a large part of the variation in abatement costs is due to mismeasurement, the coefficient on abatement costs in our regression will be biassed towards zero. If two different analyses have different amounts of 'true' variability in abatement costs but similar amounts of 'error' variability, the analysis with less 'true' variability will have larger bias.

In general, we need to pay attention to the source of variation in abatement costs 
across plants and over time, and how this corresponds with the policy questions to be addressed. If we are interested in how plants would respond to increased regulation, it would be helpful to observe variation in regulation within plants over time. If most of our variability in regulation is across plants, with relatively small variation at a specific plant over time, it will be harder to generate precise estimates of regulation's impact on productivity, and our predictions about the impact of changing regulation will have to be more tentative.

IV. Results

The variables used in the analysis are described in Table 1, with means and standard deviations presented in Table 2 . Table 2 also presents the fraction of the variable's total variation which is cross-sectional (explained by plant dummies), addressing the issue of the sources of variation for the variables we consider. Note that the annual growth rate variables (GTFP and GPAOC) are defined for only eleven, rather than twelve, years, starting with the 1979-1980 growth rates.

Comparing productivity growth rates for the three industries, we see that paper shows a substantial productivity decline (due to a poor performance in the late 1980s), with TFP declining by 2 percent per year. Steel's productivity rises during the period by 0.5 percent per year, while oil's productivity is rising by 2.4 percent per year. Since the productivity levels are calculated based on each industry's production function, they cannot be meaningfully compared across industries. 
The average paper mill spends 1.5 percent of its output on pollution abatement, while oil refineries spend only about half as much ( 0.8 percent). Steel is intermediate, spending about 1.2 percent. Steel has declining PAOC (shrinking by .04 per year) due to the contracting nature of the industry, while both oil and paper have increasing PAOC (by .02 and .07 per year, respectively). Paper shows the highest compliance rate ( 75 percent), while steel is markedly lower (64 percent) and oil is in between (70 percent). The average paper mill is more often in compliance, faces less regulatory activity and emits fewer total tons of air pollution (due to its smaller size), but has higher air pollution emissions relative to output. Steel mills are least often in compliance, face the most enforcement and emit the most pollutants in absolute terms.

The basic regression results for compliance costs are given in Table 3. The first line gives the simplest model for each industry, an ordinary regression of productivity levels on abatement cost levels. The next three models show different ways to control for differences across plants in regulation or abatement costs. Some include individual controls for plantspecific fixed effects: any part of productivity or abatement cost which remains fixed for the plant is removed from the analysis, with only variations at a given plant over time being considered in the estimation. Still others use changes in productivity and abatement costs, which also 'differences out' any fixed characteristics of the plants. The final two lines for each industry consider the possibility that plants facing more regulation might face constraints on their adoption of new productive technology, so that the level of abatement cost could be associated with the growth rate of productivity at the plant.

The results are similar in a broad sense across the three industries: plants with high 
compliance expenditures tend to have lower total factor productivity levels; plants with growing compliance expenditures tend to have slower productivity growth rates (except for steel). The coefficients for the oil industry are somewhat smaller than those for paper, while the steel industry has noticeably larger coefficients. We also find a small negative connection between pollution abatement levels and productivity growth rates.

We can use the magnitude of the pollution abatement cost coefficients in the productivity equations in Table 3 to distinguish between the 'mismeasurement' of productivity (which would lead to a PAOC coefficient of -1.0 ) and any other impacts of regulation on productivity, either positive or negative. In the simplest regressions of productivity levels on abatement costs in Table 3, the PAOC coefficient exceeds unity in magnitude, with the coefficient for steel being substantially larger than the other two. This suggests the presence of additional costs due to regulation. However, because of the imprecision in the estimated coefficients, while the coefficients are significantly different from zero we cannot reject the 'pure mismeasurement' hypothesis of -1 at the usual $5 \%$ significance level.

The other estimates in Table 3 (using growth rates of productivity, or fixed-effects) tend to show coefficients somewhat smaller in magnitude than -1 , and not significant. This could be explained by the presence of measurement error in the abatement cost variables. Since most of the variation in abatement costs is across plants, when we examine changes in abatement costs we throw away the across-plant variation (the biggest part of the total variation). Thus any measurement error is a larger part of the remaining variation, and hence exerts a stronger bias towards zero in the coefficient. However, it could also be 
interpreted as indicating some beneficial effect of regulation on productivity (though not large enough to outweigh the direct costs of compliance). Thus our evidence on the existence of additional benefits or costs due to regulation is mixed: the results could be interpreted as indicating some additional costs, but other explanations are possible.

We now turn to a two-stage analysis, allowing for the possibility that abatement costs are endogenous. Table 4 describes the variables used in the first stage analysis where we model the compliance cost variable, with regression results in Table 5. The explanatory variables in the first stage are designed to capture some of the different factors expected to increase a plant's level of compliance spending. Plants in states with especially active enforcement might face more pressure to comply, though little impact is found on abatement costs. Plants that consume more fuel tend to produce more air pollution, and both oil and paper have the expected positive signs. Plants located in non-attainment areas (where air quality fails to meet national standards) face tougher regulations than plants in cleaner areas, and these plants have higher compliance costs for all three industries.

For each industry we also include one or two dummy variables to represent aspects of the plant's technology that influence the difficulty of meeting pollution standards. For paper mills, we observe whether or not the plant uses the chemical-based Kraft technology for processing pulp, whether or not the plant operates its own water pollution treatment plant, and whether or not the plant bleaches its pulp (all factors expected to be associated with higher compliance costs). For oil refineries, we observe whether or not the plant uses catalytic cracking, a process where it is especially difficult to contain the resulting pollution: the plant's relative use of the technology (CATF2) is associated with significantly higher 
compliance costs. For steel mills, we observe whether or not the plant uses electric arc furnaces (rather than blast furnaces); electric arc is a much cleaner technology, so these plants have lower abatement costs.

Although these variables do tend to have the expected relationship with abatement costs, we find that they explain only about 20 percent of the variability in costs. This could cause problems in the second stage of the analysis, since only the predicted variability is being used in that regression. Therefore we also try including the lagged value for the plant's compliance costs in the first stage. Not surprisingly, this had substantial explanatory power, raising the R-square to .7 or .8 and generally rendering the other explanatory variables insignificant. Since lagged PAOC is predetermined it cannot be directly influenced by this period's productivity, and lagged values are commonly used as explanatory variables in first stage regressions, although lagged PAOC is obviously less 'purely' exogenous than the other explanatory variables (due to the possibility of intertemporal correlation in the determinants of PAOC).

Table 6 presents the second-stage regressions, using the predicted values of PAOC generated from the first stage regressions. Note that we do not consider the growth rate or fixed-effect versions of the regressions (as we did in Table 3). This is because all of the explanatory variables for the plants (except for lagged PAOC) are invariant over time. This means that (except for the year dummies, which are also included in the second-stage regression) there is no within-plant variation for such regressions to pick up. As expected from the low R-squares on the first-stage regressions without lagged PAOC, these predicted PAOC coefficients have little explanatory power, with standard errors nearly three times as 
large as those in Table 3 (though the coefficients are positive). When we include the lagged PAOC variable, the second-stage estimates are similar to those we found in Table 3 (with slightly larger standard errors). The magnitude of the PAOC coefficient is somewhat smaller for oil, slightly larger for paper, and noticeably larger for steel.

We also used the predicted values from the first-stage regressions to generate Hausman tests for the exogeneity of PAOC in the regressions. This involves calculating the residual value of PAOC (actual minus predicted values) and including it along with actual PAOC in a second stage regression. We present the t-statistic associated with the residual coefficients in the bottom line of Table 6. A significant coefficient on the residual indicates potential problems, but in all cases we find the residual's coefficient to be insignificant. This indicates little evidence for causality running from productivity to compliance costs, at least in a contemporaneous sense.

Another concern was the possibility of long-term quality differences across plants, correlated with both productivity and abatement costs. Table 7 shows the results of including five-year-lagged productivity levels in our basic regression of productivity levels on abatement costs. As expected, lagged productivity levels are positively (and significantly) related to current productivity. The abatement cost coefficient does fall slightly: by onequarter for oil and steel and by one-eighth for paper, although these reductions are enough to reduce the significance of the oil and steel results (with the oil coefficient being almost exactly the expected minus one). Plant quality appears to play a relatively small role in the 
observed connection between abatement costs and productivity. ${ }^{8}$

Although our focus is on the relationship between compliance costs and productivity, the other regulatory measures we gathered may be useful in obtaining a more complete picture. This is especially true because most of the variation in compliance costs is across plants, so that other plant-specific characteristics may be driving both compliance costs and productivity. The regression results for these other variables are presented in Table 8 . The results are not very strong, and rarely consistent across industries. We usually find that higher enforcement, higher emissions, and lower compliance are associated with lower productivity, but the results are not consistent in sign across industries (in fact, in each case one industry has an unexpected sign) and tend to be insignificant. Our earlier study (Gray and Shadbegian, 1993) also found insignificant results, using cross-section regressions based on average values for the regulation measures.

\section{Summary and Future Work}

Using plant-level data for three manufacturing industries, we have found a negative relationship between a plant's pollution abatement costs and its total factor productivity level. The magnitudes of the estimated coefficients suggest an impact of regulation on productivity that is somewhat larger than existing compliance cost data would suggest, but these results

${ }^{8}$ The reduction in the abatement cost coefficient could also arise if lagged abatement costs matter. In that case, the lagged productivity term picks up part of the effect of lagged abatement costs, reducing the estimated impact of current abatement costs (and possibly underestimating the total impact of abatement costs). 
depend on the specification used. Point estimates suggest that steel costs might be three times as large as expected, with oil and paper about one and a half times as large as expected, but the estimates are sufficiently imprecise that we cannot reject the hypothesis that existing estimates of compliance costs (based on abatement cost surveys) are about right. It does not appear that regulation imposes productivity benefits large enought to outweigh the measured compliance costs, but even this cannot be rejected if we focus on the analysis of productivity changes over time, or otherwise control for unobserved differences across plants. Our results for other measures of regulation, such as enforcement, compliance, and emissions, show little significant relationships with productivity. More often than not, plants with higher enforcement, lower compliance, or more emissions tend to have lower productivity levels, but the results are neither significant nor consistent.

Several avenues of research remain to be pursued. We are looking at other environmental areas with more limited data (water and toxic waste pollution) and at OSHA regulation, to provide a broader coverage for the enforcement and compliance measures for the plant. We are considering MIMIC models which would allow us to combine several indicators of the regulation faced by a plant into an overall index of regulation, to see whether that index does a better job explaining productivity than the individual indicators do. Finally, we are working on more detailed models of the production function, allowing the influence of regulation to affect labor and capital differently, estimating the effect of regulation on employment and investment, and testing possible explanations of why regulation affects productivity. 


\section{REFERENCES}

Barbera, Anthony J., and Virginia D. McConnell, "Effects of Pollution Control on Industry Productivity: A Factor Demand Approach," Journal of Industrial Economics, V. 35 n. 2 (December 1986), pp. 161-172.

Clark, Kim B., "The Impact of Unionization on Productivity: A Case Study," Industrial and Labor Relations Review, v. 33 (1980), pp. 451-69.

Deily, Mary E. and Wayne B. Gray, "Enforcement of Pollution Regulations in a Declining Industry," Journal of Environmental Economics and Management, v. 21 (Fall 1991), pp. 260-274.

Denison, Edward P., Accounting for Slower Economic Growth: The U.S. in the 1970s, (Washington: The Brookings Institution) 1979.

Gollop, Frank M., and Mark J. Roberts, "Environmental Regulations and Productivity Growth: The Case of Fossil-Fueled Electric Power Generation," Journal of Political Economy, v. 91 (August 1983), pp. 654-674.

Gray, Wayne B., "The Cost of Regulation: OSHA, EPA and the Productivity Slowdown", American Economic Review, v. 77 (December 1987), pp. 998-1006.

Press), 1986.

, Productivity versus OSHA and EPA Regulations, (Ann Arbor: UMI Research and Ronald J. Shadbegian, "Environmental Regulation and Manufacturing

Productivity at the Plant Level," CES Discussion Paper 93-6, March 1993.

Hoerger, Fred, William H. Beamer, and James S. Hanson, "The Cumulative Impact of Health, Environmental, and Safety Concerns on the Chemical Industry During the Seventies, "Law and Contemporary Problems, v. 46 (Summer 1983), pp. 59-107.

Leibenstein, Harvey, "Allocative Efficiency versus X-Efficiency", American Economic Review, v. 56 (June 1966), pp. 392-415.

Lichtenberg, Frank R., and Donald Siegel, "The Impact of R\&D Investment on Productivity - New Evidence Using Linked R\&D-LRD Data, "Economic Inquiry, v. 29 (1990), pp. 2-13.

, "The Effects of Leveraged Buyouts on Productivity and Related Aspects of Firm Behavior," Journal of Finance and Economics, v. 27 (1990), pp. 165-194. 
McGuckin, Robert H., and George A. Pascoe, "The Longitudinal Research Database: Status and Research Possibilities," Survey of Current Business, 1988.

Nguyen, Sang V. and Edward C. Kokkelenberg, "Measuring Total Factor Productivity, Technical Change, and the Rate of Returns to Research and Development," Journal of Productivity Analysis, v. 2 (1992), pp. 269-282.

Oates, Wallace E., Karen Palmer, and Paul R. Portney, "Environmental Regulation and International Competitiveness: Thinking about the Porter Hypothesis, " Resources for the Future Discussion Paper 94-02, November 1993.

Porter, Michael E., "America's Green Strategy," Scientific American, April 1991, p. 168. , The Competitive Advantage of Nations (New York: The Free Press) 1990.

U.S. Bureau of the Census, Pollution Abatement Costs and Expenditures. 1990 MA200(90)-1 Washington: U.S. Government Printing Office, 1992.

Viscusi, W. Kip, "Frameworks for Analyzing the Effects of Risk and Environmental Regulation on Productivity," American Economic Review, v. 73 (September 1983), pp. 793-801. 
Table 1

Variable Descriptions

\begin{tabular}{|c|c|}
\hline Variable & Description \\
\hline LTFP & $\begin{array}{l}\text { Total factor productivity level (based on } \\
\text { equation } 1 \text { and coefficients for each } \\
\text { industry from equation 2) }\end{array}$ \\
\hline GTFP & Annual growth rate of LTFP \\
\hline PAOC & $\begin{array}{l}\text { Pollution abatement operating cost, divided } \\
\text { by plant 'capacity' (top two years of } \\
\text { shipments in period) }\end{array}$ \\
\hline GPAOC & Annual growth rate of PAOC \\
\hline EMIT & $\begin{array}{l}\text { Total emissions (thousand tons/year) of five } \\
\text { 'criteria' air pollutants (particulates, } \\
\text { so2, Nox, CO, and hydrocarbons) }\end{array}$ \\
\hline REMIT & $\begin{array}{l}\text { EMIT per dollar of plant 'capacity' <used in } \\
\text { regressions> }\end{array}$ \\
\hline COMP & $\begin{array}{l}\text { Compliance status with air pollution } \\
\text { regulations ( } 0 \text { if in violation during any } \\
\text { month of the year, } 1 \text { if not) }\end{array}$ \\
\hline ACT & $\begin{array}{l}\text { Number of air pollution enforcement actions } \\
\text { in year (from EPA's Compliance Data System) }\end{array}$ \\
\hline LACT & $\log (A C T)$ <used in regressions> \\
\hline INSP & $\begin{array}{l}\text { Number of air pollution inspections in year } \\
\text { (from EPA's Compliance Data System) }\end{array}$ \\
\hline LINSP & $\log ($ INSP) $<$ used in regressions> \\
\hline
\end{tabular}


Table 2

Descriptive statistics

(1979-1990 Annual Data)

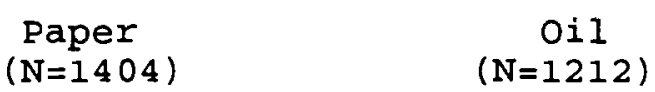

Steel

$(\mathrm{N}=612)$

\begin{tabular}{|c|c|c|c|c|c|c|c|c|c|}
\hline Variable & e mean & $(\mathrm{sd})$ & $\begin{array}{l}\frac{\gamma}{8} \\
\operatorname{lan} t^{2}\end{array}$ & mean & $(s d)$ & $\begin{array}{l}\frac{8}{8} \\
\operatorname{ant}^{2}\end{array}$ & mean & $(s d)$ & $\begin{array}{l}\frac{\gamma}{\gamma} \\
\operatorname{ant} t^{2}\end{array}$ \\
\hline LTFP & 101.840 & $(23.6)$ & $32 \%$ & 79.250 & $(20.0)$ & 268 & 147.600 & $(22.8)$ & 298 \\
\hline GTFP $^{1}$ & -2.040 & $(16.7)$ & $1 \frac{q}{8}$ & 2.440 & $(15.8)$ & $2 \%$ & 0.538 & $(24.8)$ & $1 \frac{8}{8}$ \\
\hline PAOC & 1.509 & $(1.18)$ & $81 \frac{8}{8}$ & 0.802 & $(0.89)$ & $70 \%$ & 1.249 & $(0.78)$ & $51 \%$ \\
\hline GPAOC $^{1}$ & 0.015 & $(0.53)$ & $2 q$ & 0.072 & $(0.36)$ & $6 \frac{8}{8}$ & -0.042 & $(0.52)$ & $2 \frac{8}{8}$ \\
\hline EMIT & 7.901 & $(11.0)$ & $76 \frac{8}{8}$ & 21.663 & $(45.7)$ & $57 \frac{8}{8}$ & 26.573 & $(50.1)$ & $6 \frac{8}{8}$ \\
\hline REMIT & 0.146 & $(0.27)$ & $56 \frac{8}{8}$ & 0.121 & $(0.31)$ & $53 \frac{8}{8}$ & 0.082 & $(0.09)$ & 698 \\
\hline COMP & 0.747 & $(0.43)$ & $32 \frac{8}{2}$ & 0.697 & $(0.45)$ & 298 & 0.644 & $(0.47)$ & $54 \frac{8}{8}$ \\
\hline ACT & 3.846 & $(5.61)$ & $53 \frac{8}{8}$ & 7.245 & $(12.6)$ & 538 & 11.930 & $(22.2)$ & $55 \%$ \\
\hline ILACT & 1.180 & $(0.84)$ & $52 \frac{2}{8}$ & 1.623 & $(0.93)$ & $58 \frac{8}{8}$ & 1.868 & $(1.11)$ & $55 \%$ \\
\hline INSP & 1.345 & $(1.37)$ & 398 & 1.952 & $(1.90)$ & $38 \frac{8}{8}$ & 3.843 & $(6.33)$ & $48 \frac{8}{8}$ \\
\hline LINSP & 0.723 & $(0.50)$ & $34 \%$ & 0.916 & $(0.57)$ & $36 \frac{8}{8}$ & 1.190 & $(0.80)$ & $47 \frac{8}{8}$ \\
\hline
\end{tabular}

1 GTFP and GPAOC are growth rates, so they are only available for 11 years rather than 12. The first observation is the 1979-80 growth rate, with correspondingly smaller sample sizes.

2 splant is the percentage of the variance explained by the identity of the plant (the $\mathrm{R}$-squared obtained by regressing the variable on $a$ complete set of plant dummies) 
TABLE 3

Basic Regressions

\begin{tabular}{|c|c|c|c|c|c|c|c|}
\hline Industry & Dep Var & PAOC & $\begin{array}{l}\text { Controls } \\
\text { GPAOC }\end{array}$ & Year & Plant & $\mathrm{R}^{2}$ & $\mathbf{N}$ \\
\hline \multirow[t]{6}{*}{ Paper } & LTFP & $\begin{array}{c}-1.737 \\
(0.437)\end{array}$ & & $\mathrm{X}$ & & .354 & 1404 \\
\hline & LTFP & $\begin{array}{c}-0.546 \\
(0.809)\end{array}$ & & $\mathrm{x}$ & $\mathrm{x}$ & .666 & 1404 \\
\hline & GTFP & & $\begin{array}{l}-0.756 \\
(0.712)\end{array}$ & $\mathrm{x}$ & & .433 & 1287 \\
\hline & GTFP & & $\begin{array}{l}-0.855 \\
(0.745)\end{array}$ & $\mathrm{X}$ & $\mathrm{X}$ & .447 & 1287 \\
\hline & GTFP & $\begin{array}{l}-0.196 \\
(0.305)\end{array}$ & & $\mathrm{x}$ & & .433 & 1287 \\
\hline & GTFP & $\begin{array}{l}-0.609 \\
(0.798)\end{array}$ & & $\mathrm{X}$ & $\mathrm{X}$ & .447 & 1287 \\
\hline \multirow[t]{6}{*}{ Oil } & LTFP & $\begin{array}{l}-1.350 \\
(0.553)\end{array}$ & & $\mathrm{x}$ & & .357 & 1212 \\
\hline & LTFP & $\begin{array}{l}-0.972 \\
(0.945)\end{array}$ & & $\mathrm{x}$ & $\mathrm{X}$ & .618 & 1212 \\
\hline & GTFP & & $\begin{array}{c}-0.569 \\
(1.267)\end{array}$ & $\mathrm{x}$ & & .155 & 1111 \\
\hline & GTFP & & $\begin{array}{c}-0.493 \\
(1.358)\end{array}$ & $\mathrm{X}$ & $\mathrm{X}$ & .173 & 1111 \\
\hline & GTFP & $\begin{array}{c}-0.067 \\
(0.513)\end{array}$ & & $\mathrm{X}$ & & .155 & 1111 \\
\hline & GTFP & $\begin{array}{l}-0.579 \\
(1.155)\end{array}$ & & $\mathrm{x}$ & $\mathrm{X}$ & .173 & 1111 \\
\hline \multirow[t]{6}{*}{ Steel } & LTFP & $\begin{array}{l}-3.280 \\
(1.181)\end{array}$ & & $\mathrm{x}$ & & .082 & 612 \\
\hline & LTFP & $\begin{array}{l}-2.755 \\
(1.520)\end{array}$ & & $\mathrm{X}$ & $\mathrm{X}$ & .368 & 612 \\
\hline & GTFP & & $\begin{array}{c}0.264 \\
(2.109)\end{array}$ & $\mathrm{X}$ & & .047 & 561 \\
\hline & GTFP & & $\begin{array}{c}0.349 \\
(2.230)\end{array}$ & $\mathrm{X}$ & $\mathrm{X}$ & .054 & 561 \\
\hline & GTFP & $\begin{array}{l}-0.648 \\
(1.406)\end{array}$ & & $\mathrm{x}$ & & .047 & 561 \\
\hline & GTFP & $\begin{array}{l}-1.497 \\
(2.196)\end{array}$ & & $\mathrm{X}$ & $\mathrm{X}$ & .055 & 561 \\
\hline
\end{tabular}


Table 4

Exogenous Variables

(used to explain PAOC in two-stage model)

STENF - air pollution enforcement actions per plant reported in EPA's Compliance Data System for the state (1984-1987)

ENETVS - energy spending / total value of shipments (1972)

DIRTY - plant is located in a county which fails to meet air EPA quality standards (dummy variable)

KRAFT - (paper) uses Kraft technology for paper-making BLEACH - (paper) bleaches pulp

TREAT - (paper) has water treatment plant on site

CATF1 - (oil) uses catalytic cracking technique

CATF2 - (oil) ratio of catalytic cracking capacity to other capacity

EARC - (steel) uses electric arc furnaces

Descriptive Statistics

Paper

STENF

ENETVS

DIRTY

KRAFT

BLEACH

TREAT

CATF1

CATF2

EARC

N

$$
\begin{aligned}
4.09 & (1.91) \\
.06 & (.02) \\
.48 & (.50) \\
.39 & (.49) \\
.41 & (.49) \\
.56 & (.50)
\end{aligned}
$$

Oil

$$
\begin{array}{ll}
4.92 & (1.62) \\
.02 & (.02) \\
.65 & (.48)
\end{array}
$$

$$
\begin{array}{ll}
4.44 & (2.13 \\
.14 & (.05) \\
.80 & (.40)
\end{array}
$$

$$
\begin{aligned}
.74 & (.44) \\
1.22 & (1.62)
\end{aligned}
$$

1404

1212
$.49 \quad(.50)$

612 
Table 5

First-Stage Regressions

(dep var=PAOC)

Paper Oil Steel

\begin{tabular}{|c|c|c|c|c|c|c|}
\hline CONST & $\begin{array}{c}0.7754 \\
(0.1690)\end{array}$ & $\begin{array}{c}-0.1111 \\
(0.0805)\end{array}$ & $\begin{array}{c}0.4791 \\
(0.1247)\end{array}$ & $\begin{array}{l}-0.0859 \\
(0.0564)\end{array}$ & $\begin{array}{c}1.5764 \\
(0.1522)\end{array}$ & $\begin{array}{c}0.3640 \\
(0.1073)\end{array}$ \\
\hline LPAOC & - & $\begin{array}{c}0.8919 \\
(0.0130)\end{array}$ & - & $\begin{array}{c}0.9637 \\
(0.0139)\end{array}$ & - & $\begin{array}{c}0.733 \\
(0.0264)\end{array}$ \\
\hline STENF & $\begin{array}{c}0.0092 \\
(0.0167)\end{array}$ & $\begin{array}{l}-0.0030 \\
(0.0080)\end{array}$ & $\begin{array}{l}-0.0585 \\
(0.0154)\end{array}$ & $\begin{array}{l}-0.0016 \\
(0.0071)\end{array}$ & $\begin{array}{c}0.0082 \\
(0.0147)\end{array}$ & $\begin{array}{c}0.0044 \\
(0.0097)\end{array}$ \\
\hline ENETVS & $\begin{array}{c}2.9460 \\
(1.3130)\end{array}$ & $\begin{array}{c}0.5242 \\
(0.6302)\end{array}$ & $\begin{array}{c}6.0727 \\
(1.3750)\end{array}$ & $\begin{array}{c}0.4711 \\
(0.6338)\end{array}$ & $\begin{array}{c}-0.6651 \\
(0.5672)\end{array}$ & $\begin{array}{c}-0.0847 \\
(0.3751)\end{array}$ \\
\hline DIRTY & $\begin{array}{c}0.3732 \\
(0.0628)\end{array}$ & $\begin{array}{c}0.0252 \\
(0.0305)\end{array}$ & $\begin{array}{c}0.1885 \\
(0.0528)\end{array}$ & $\begin{array}{c}0.0020 \\
(0.0243)\end{array}$ & $\begin{array}{c}0.1399 \\
(0.0753)\end{array}$ & $\begin{array}{c}0.0678 \\
(0.0498)\end{array}$ \\
\hline KRAFT & $\begin{array}{c}0.1236 \\
(0.0846)\end{array}$ & $\begin{array}{c}0.0351 \\
(0.0406)\end{array}$ & & & & \\
\hline BLEACH & $\begin{array}{c}-0.0289 \\
(0.0883)\end{array}$ & $\begin{array}{c}0.0495 \\
(0.0423)\end{array}$ & & & & \\
\hline TREAT & $\begin{array}{c}0.6462 \\
(0.0789)\end{array}$ & $\begin{array}{c}0.0479 \\
(0.0387)\end{array}$ & & & & \\
\hline CATF1 & & & $\begin{array}{l}-0.0325 \\
(0.0599)\end{array}$ & $\begin{array}{l}-0.0049 \\
(0.0274)\end{array}$ & & \\
\hline CATF2 & & & $\begin{array}{c}0.1164 \\
(0.0167)\end{array}$ & $\begin{array}{c}0.0163 \\
(0.0078)\end{array}$ & & \\
\hline EARC & & & & & $\begin{array}{c}-0.4766 \\
(0.0606)\end{array}$ & $\begin{array}{c}-0.0567 \\
(0.0421)\end{array}$ \\
\hline $\begin{array}{l}\mathrm{R} 2 \\
\mathrm{~N}\end{array}$ & $\begin{array}{r}.206 \\
1404\end{array}$ & $\begin{array}{r}.832 \\
1287\end{array}$ & $\begin{array}{r}210 \\
1212\end{array}$ & $\begin{array}{r}854 \\
1111\end{array}$ & $\begin{array}{r}.173 \\
612\end{array}$ & $\begin{array}{l}655 \\
561\end{array}$ \\
\hline
\end{tabular}

All regressions include year dummies. 
Table 6

Second-Stage Regressions

(dep var=LTFP)

\begin{tabular}{|c|c|c|c|c|c|c|}
\hline \multirow[b]{2}{*}{$\begin{array}{l}\text { lst stage } \\
\text { w/LPAOC }\end{array}$} & \multicolumn{2}{|c|}{ Paper } & \multicolumn{2}{|c|}{ Oil } & \multicolumn{2}{|c|}{ Steel } \\
\hline & no & yes & no & yes & no & yes \\
\hline $\begin{array}{l}\text { Predicted } \\
\text { PAOC }\end{array}$ & $\begin{array}{c}-0.075 \\
(1.024)\end{array}$ & $\begin{array}{c}-2.086 \\
(0.463)\end{array}$ & $\begin{array}{c}0.126 \\
(1.612)\end{array}$ & $\begin{array}{c}-1.095 \\
(0.539)\end{array}$ & $\begin{array}{c}0.722 \\
(3.520)\end{array}$ & $\begin{array}{l}-5.019 \\
(1.647)\end{array}$ \\
\hline $\mathrm{R} 2$ & .347 & .372 & .353 & .356 & .064 & .076 \\
\hline$N$ & 1404 & 1287 & 1212 & 1111 & 612 & 561 \\
\hline
\end{tabular}

The above regressions involve regressing LTFP on the predicted PAOC values generated by the first-stage regressions presented in Table 5. For each industry two different predicted PAOC values are used: one includes LPAOC in the first-stage model and the other doesn't.

\begin{tabular}{ccccccc} 
& \multicolumn{2}{c}{ Exogeneity Tests } \\
\multicolumn{2}{c}{ Paper } & \multicolumn{2}{c}{ Oil } & \multicolumn{2}{c}{ Steel } \\
-1.81 & -0.23 & 0.96 & -0.86 & 1.39 & 1.65
\end{tabular}

The above exogeneity tests involve regressing LTFP on both actual and residual PAOC. Each industry has two test values reported, corresponding to the two different first-stage regressions (excluding or including LPAOC). The statistics given are t-statistics on the residual PAOC measure (based on the firststage regressions). A significant t-statistic indicates possible endogeneity of PAOC (or at least the rejection of the null hypothesis which includes exogenous PAOC).

All sets of regressions include year dummies. 
Table 7

Regressions including lagged TFP (dep var=LTFP)

Paper Oil Steel

$\begin{array}{lccc}\text { PAOC } & -1.51 & -1.04 & -2.36 \\ & (0.434) & (0.537) & (1.38) \\ \text { 5-year } & 0.384 & 0.347 & 0.257 \\ \text { lagged } & (0.027) & (0.027) & (0.047) \\ \text { LTFP } & & & \\ \text { N } & 1404 & 1212 & 612 \\ \text { R2 } & .437 & .434 & .123\end{array}$

Each regression also includes year dummies. 


\section{Table 8 \\ Other Regulatory Variables (dep var=LTFP)}

$\begin{array}{lccc} & \text { Paper } & \text { Oil } & \text { Steel } \\ \text { REMIT } & -0.0086 & -0.0228 & 0.2413 \\ & (0.0191) & (0.0149) & (0.1041) \\ \text { COMP } & 0.0018 & 0.0115 & -0.0061 \\ & (0.0120) & (0.0104) & (0.0460) \\ \text { LACT } & -0.0002 & 0.0087 & -0.0128 \\ & (0.0062) & (0.0051) & (0.0084) \\ \text { LINSP } & 0.0114 & -0.0027 & -0.0152 \\ & (0.0105) & (0.0085) & (0.0117) \\ N & 1404 & 1212 & 612\end{array}$

Each pair of numbers above comes from a separate regression of LTFP on year dummies and that particular regulatory variable (along with year dummies).

The numbers presented in the table are the coefficient and standard error for the regulatory variable. 